\title{
ANALISIS TINGKAT PENERIMAAN SISTEM E-LEARNING MENGGUNAKAN BLOG GRATIS SEBAGAI ALTERNATIF MEDIA PEMBELAJARAN PADA GURU
}

\author{
Faizatul Amalia ${ }^{1}$, Adam Hendra Brata ${ }^{2}$, Rizki Tri Sulistyo ${ }^{3}$, Andre Diofanu ${ }^{4}$ \\ ${ }^{1,2,3,4}$ Fakultas Ilmu Komputer, Universitas Brawijaya \\ Email: ${ }^{1}$ faiz_amalia@ub.ac.id, ${ }^{2}$ adam@ub.ac.id
}

(Naskah masuk: 01 Februari 2018, diterima untuk diterbitkan: 08 Agustus 2018)

\begin{abstract}
Abstrak
Blog merupakan sebuah media yang digunakan untuk mem-posting berita, informasi, video berbasis website. Jenis blog yang ada saat ini yaitu yang berbayar atau yang bebas biaya seperti Blogspot, wordpress dan lain-lain. Saat ini, pengguna blog berjumlah banyak. Hal ini dikarenakan fungsi dari blog tidak hanya untuk posting berita atau informasi tetapi pembaca bisa memberikan saran terkait konten ataupun bertanya kepada blogger tersebut. Dalam dunia pendidikan, blog bisa digunakan sebagai media pembelajaran yang dapat membantu posting materi pelajaran, pengumuman ulangan harian, ataupun diskusi terkait materi pelajaran. Namun penggunaan dari blog sebagai media pembelajaran kurang terlihat. Tujuan penelitian ini diantaranya untuk mengetahui persentase guru dalam menggunakan blog gratis sebagai media pembelajaran alternatif pada SMK, dan mengimplementasikan UTAUT sebagai model dasar dalam penilaian penerimaan teknologi blog sebagai media pembelajaran alternatif pada SMK. Metode UTAUT (Unified Theory of Acceptance and Use of Technology) ini digunakan untuk menguji penerimaan teknologi oleh user terhadap penggunaan blog sebagai media pembelajaran di sekolah. Populasi dari penelitian ini adalah semua guru SMK yang ada di Kota Malang. Dengan teknik random sampling pada 61 guru SMK. Instrumen yang digunakan pada penelitian ini adalah kuesioner yang menggunakan indikator dari metode UTAUT. Hasil yang didapatkan berupa blog gratis yang paling banyak digunakan oleh guru SMK sebagai media pembelajaran alternative adalah (1) blogspot sebesar $63 \%$, wordpress sebesar $18.5 \%$, Edmodo sebesar $17.4 \%$ dan lainnya sebesar $1.1 \%$; (2) hasil dari implementasi kuesioner yang menggunakan metode UTAUT menghasilkan effort expectancy sebesar $94.02 \%$, performance expectancy sebesar $89.50 \%$, social influence sebesar $88.04 \%$, supporting facilities sebesar $86.04 \%$, use behavior sebesar $85.71 \%$ dan behavioral intention sebesar $84.39 \%$.
\end{abstract}

Kata kunci: media pembelajaran, metode UTAUT, guru, SMK, penerimaan, teknologi, blog

\section{ANALYSIS OF E-LEARNING SYSTEM ACCEPTANCE LEVEL USING FREE BLOG AS AN ALTERNATIVE MEDIA LEARNING FOR TEACHERS}

\begin{abstract}
Blog is a medium used to post news, information, video-based websites. The types of blogs that exist today are paid or free of charges such as Blogspot, WordPress, and others. Currently, blog users are numerous. This is because the function of the blog not only for posting news or information but the reader can provide advice related to the content or ask the blogger. In the world of education, blogs can be used as a medium of learning that can help post the subject matter, daily repetition announcements, or discussion related subject matter. But the use of the blog as a learning medium is less visible. This research has some intentions are: discovering the percentage of teachers which is used a free blog as an alternative learning media, implementing the UTAUT method to evaluate in accepting technology in free blog as an alternative learning media. The method of UTAUT (Unified Theory of Acceptance and Use of Technology) is used to test the acceptance of technology by the user against the use of blog as a medium of learning in school. The Vocational Teachers of Malang are being used in this research as a population. From this population, we should use the sampling method. And the sampling method is used random sampling which is 61 samples from all of the teacher in Vocational School in Malang. The result from this research are: (1) Blogspot is the most used by teacher in vocational school as learning media is about 63\%, then wordpress is about 18.5\%, Edmodo is about 17.4\% and other is about 1.1\%; (2) and at about $94.02 \%$ in effort expectancy, $89.50 \%$ in performance expectancy, $88.04 \%$ in social influence, $86.04 \%$ in supporting facilities, $85.71 \%$ in use behavior, and $84.39 \%$ in behavioral intention.
\end{abstract}

Keywords: learning media, UTAUT method, teachers, vocational school, accepting, technology 


\section{PENDAHULUAN}

Indonesia merupakan negara yang sedang berkembang dan telah mengikuti MEA. MEA yang memiliki kepanjangan masyarakat ekonomi ASEAN merupakan program untuk semua anggota negara ASEAN yang memiliki tujuan untuk peningkatan stabilitas perekonomian dan memperkuat kawasan ekonomi antar negara ASEAN (Pujiani, 2014). Dengan MEA diberlakukan di Indonesia, maka akan terjadi aliran bebas barang, jasa, investasi dan tenaga kerja terdidik dari dan ke masing-masing bagian dari negara ASEAN.

Hal ini membuat sektor di bidang pendidikan maupun ekonomi berlomba-lomba untuk menyiapkan sumber daya manusia yang kompeten. Seperti halnya ujian kompetensi keahlian yang diselenggarakan di tingkat sekolah menengah kejuruan. Uji Kompetensi Keahlian (UKK) adalah bagian dari intervensi Pemerintah dalam menjamin mutu pendidikan pada satuan pendidikan Sekolah Menengah Kejuruan. Pelaksanaan UKK bertujuan untuk mengukur pencapaian kompetensi siswa pada level tertentu sesuai Kompetensi Keahlian yang ditempuh selama masa pembelajaran di SMK (Damarjati, 2016).

Untuk menghasilkan siswa dan siswi yang berkompeten, diperlukan metode pembelajaran, model pembelajaran serta media pembelajaran yang tepat yaitu yang bisa menunjang kegiatan belajar mengajar di kelas ataupun di luar kelas. Bentuk media pembelajaran pun juga sangat bervariasi seiring dengan perkembangan teknologi yang ada. E-learning merupakan sebuah media pembelajaran berbasis elektronik yang bisa digunakan untuk kegiatan pembelajaran jarak jauh (Chandrawati, 2010).

Bentuk dari e-learning yang sudah dikembangkan misalnya edmodo, moodle dan weblog. Blog sendiri merupakan akronim dari weblog. Situs ini biasanya dapat diakses oleh semua pengguna internet sesuai dengan topik dan tujuan pengguna blog tersebut (Herutomo, 2010). Weblog atau blog juga bisa dimanfaatkan sebagai media pembelajaran alternatif. Karena karakteristik yang dimiliki blog bisa digunakan sebagai media pembelajaran. Penggunaan blog sebagai media pembelajaran bertujuan untuk mempermudah siswa/i dalam memperkaya pengetahuan dan aktif untuk diskusi dengan guru ataupun antar teman.

Di tingkat sekolah menengah kejuruan, blog bisa mendukung kegiatan pembelajaran. Meskipun pengguna perangkat bergerak seperti telepon pintar (smartphone) ataupun tablet dimiliki oleh siswa maupun siswi dan guru. Pelatihan juga sering dilaksanakan untuk membantu guru membuat blog menjadi sarana belajar yang lain. Namun pada kenyataannya, jumlah persentase guru sebagai pengguna blog tidak begitu signifikan. Siswa dan siswi juga enggan mengakses blog guru dan tidak semua guru juga menggunakan blog sebagai media pembelajaran.

Sebuah teknologi dikatakan berhasil apabila bisa dimanfaatkan oleh user semaksimal mungkin dan diterima oleh user. Oleh karena itu penelitian ini dilakukan untuk mengetahui tingkat penerimaan elearning dalam hal ini menggunakan blog gratis sebagai media pembelajaran alternatif di sekolah menengah kejuruan dengan menggunakan model UTAUT (Unified Theory of Acceptance and Use of Technology).

Dengan mengetahui persentase penerimaan penggunaan blog sebagai media pembelajaran alternative menggunakan model UTAUT, penggunaan blog gratis sebagai media pembelajaran alternative bisa dimaksimalkan. Sehingga blog gratis yang digunakan, bisa membantu siswa untuk belajar mandiri dan aktif mencari informasi. Metode pembelajaran ini termasuk ke dalam pendekatan student centered learning. Pendekatan ini akan membantu siswa untuk membangun pengetahuannya sendiri.

Penelitian ini memfokuskan kepada blog gratis, karena bentuk media pembelajaran yang tersedia bisa melalui blog. Penelitian yang dilakukan oleh Liu pada tahun 2016, tentang penggunaan video blog untuk mengoptimasi hasil belajar di perguruan tinggi (Liu, 2016). Penelitian lainnya juga dilakukan oleh Kathpalia pada tahun 2016. Pada penelitian tersebut, penggunaan blog siswa dapat digunakan untuk meningkatkan argumentasi yang mendukung kurikulum di perguruan tinggi (Sujata S. Kathpalia, 2016).

Model UTAUT dipilih peneliti sebagai model untuk menilai seberapa besar penerimaan teknologi. UTAUT adalah adopsi dari beberapa model penerimaan teknologi seperti Theory of Reasoned Action (TRA), Technology of Acceptance Model (TAM), serta Social Cognitive Theory (SCT) (Venkatesh dalam Pradana, 2015). UTAUT memiliki aturan dalam pemilihan responden yang didasarkan pada empat kriteria yaitu umur, pengalaman menggunakan sistem, gender dan kemauan penggunaan dari sistem.

\section{KAJIAN PUSTAKA}

Blog adalah kependekan dari WeBlog, istilah ini pertama kali digunakan oleh Jorn Barger pada bulan Desember 1997. Jorn Barger menggunakan istilah WeBlog untuk menyebut kelompok website pribadi yang selalu di-update secara kontinyu dan berisi link-link ke website lain yang mereka anggap menarik disertai dengan komentar-komentar mereka sendiri.

Media pembelajaran merupakan sebuah perantara antara guru dengan siswa. Tujuan media pembelajaran adalah untuk memudahkan siswa 
dalam memahami suatu materi. Bentuk dari media pembelajaran adalah blog. Kelebihan blog sebagai media pembelajaran adalah tampilan dari materi tidak monoton dan tidak membuat siswa bosan dalam membaca materi pelajaran (SEAMOLEC 2017).

UTAUT adalah sebuah model penerimaan teknologi yang diusulkan oleh Viswanath Venkatesh, dkk pada tahun 2003 (Venkatesh, et al. 2003). Dalam model UTAUT (Gambar 1), terdapat empat faktor dan empat hal yang digunakan dalam memengaruhi user acceptance dan usage behavior, yaitu: performance expectancy, effort expectancy, social influence, dan facilitating conditions (Venkatesh et al., 2003; Zhou, Lu and Wang, 2010; Parameswaran, Kishore and Li, 2015).

Penelitian pertama yang dilakukan oleh Kurniabudi dengan judul "Analisis perilaku penerimaan edmodo pada perkuliahan dengan model UTAUT" yang dilaksanakan pada tahun 2016.

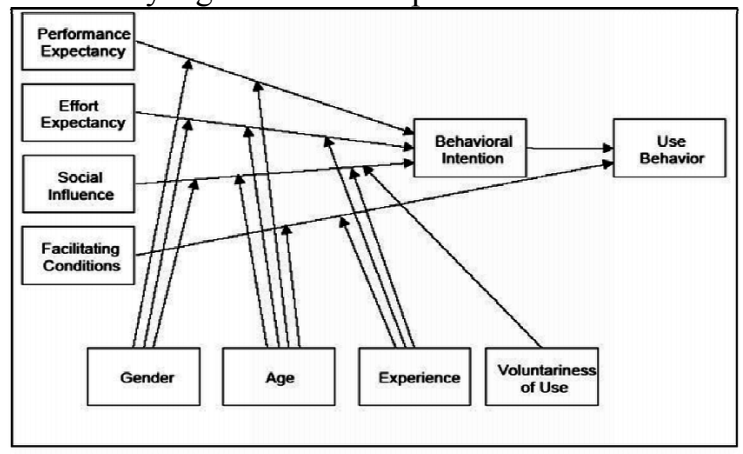

Gambar 1. Model UTAUT (Venkatesh, et al., 2003)

Penelitian ini membuktikan bahwa performance expectancy, price value dan habit secara signifikan memengaruhi behavioral intentian terhadap penggunaan Edmodo pada perkuliahan. Sedangkan effort expectancy, social influence, hedonic motivation dan facilitation condition tidak berpengaruh signifikan terhadap behavioral intention. Kemampuan model untuk memprediksi penerimaan penggunaan Edmodo dalam perkuliahan cukup substansial, hal ini ditunjukkan dengan nilai R2 sebesar 0.639 atau mendekati 0.670. Artinya kehandalan model ini dalam memprediksi sebesar 63.9\%. Berdasarkan effect size pada model dalam penelitian ini, habit memiliki efek yang besar dengan nilai 0.456 .

Penelitian kedua dilakukan oleh Fajar Pradana, Aditya Rachmadi, Fitra A. Bachtiar dengan judul "Penilaian faktor penerimaan teknologi blender learning di PTIIK Universitas Brawijaya dengan metode UTAUT" pada tahun 2015. Berdasarkan penelitian ini, dapat disimpulkan bahwa terdapat delapan faktor yang berpengaruh terhadap penerimaan teknologi pada PTIIK-UB; Dosen lebih memilih sistem lain seperti blog dosen dan dropbox karena beranggapan unjuk kerja dari e-learning kurang maksimal dan tidak memberikan dampak yang signifikan terhadap kemudahan dalam proses belajar mengajar; Menggunakan e-learning dosendosen percaya tidak akan meningkatkan image terhadap rekan sejawatnya serta faktor sosial seperti keberadaan rekan-rekan yang menggunakan $e$ learning tidak serta merta membuat rekan dosen yang lain menggunakan sistem ini; E-learning tidak terintegrasi dengan sistem yang ada di PTIIK UB seperti SIAM dan SIADO. Hal ini menyebabkan motivasi dalam menggunakan e-learning menurun.

Penelitian ketiga dilakukan oleh I Gusti Nyoman Sedana, St. Wisnu Wijaya yang berjudul "Penerapan model UTAUT untuk memahami penerimaan dan penggunaan Learning Management System Studi Kasus: Experential Learning ELearning of Sanata Dharma University" pada tahun 2009. Hasil penelitian menunjukkan bahwa UTAUT adalah alat yang berguna untuk menjelaskan penerimaan dan penggunaan Exelsa oleh mahasiswa Universitas Sanata Dharma. Hasil analisis deskriptif memperlihatkan bahwa sebagian besar responden memiliki tingkat performance expectancy, effort expectancy, social influence, facilitating conditions, dan use behavior yang tergolong tinggi, sementara tingkat behavioral intention sebagian besar responden tergolong sedang. Hasil pengujian dengan korelasi Spearman menunjukkan bahwa performance expectancy, effort expectancy, social influence, dan facilitating condition masing-masing memiliki korelasi positif dan signifikan (pvalue $<0.01$ ) terhadap behavioral intention. Begitu pula behavioral intention memiliki korelasi yang positif dan signifikan dengan use behavior (pvalue $<0.05$ ). Sementara facilitating condition tidak memiliki korelasi yang signifikan dengan use behavior.

\section{METODE PENELITIAN}

Penelitian ini menggunakan pendekatan penelitian kuantitatif dengan metode survey. Tahapan dari penelitian ini dapat dilihat pada Gambar 2.

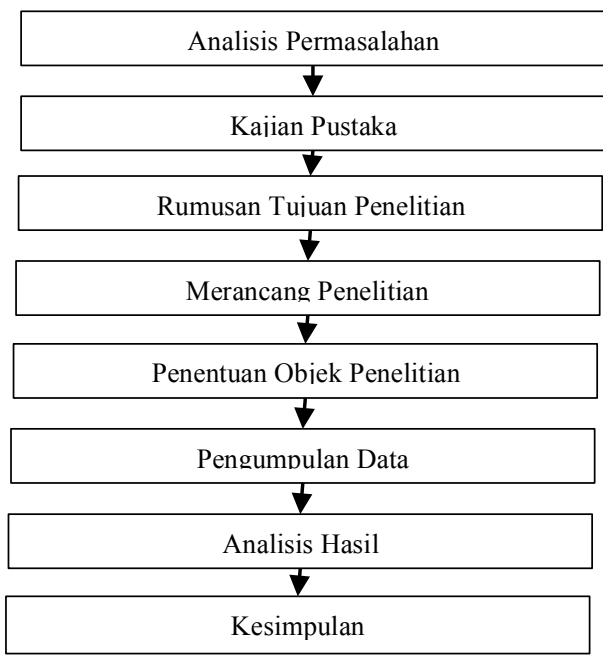

Gambar 2. Tahapan Penelitian 


\subsection{Analisis Permasalahan}

Pada tahap ini, permasalahan yang muncul digali dengan melakukan observasi ke lapangan dan melalui wawancara dengan guru terkait penggunaan media pembelajaran. Observasi dilakukan kepada guru yang menggunakan media pembelajaran blog.

\subsection{Kajian Pustaka}

Kajian pustaka atau landasan teoritis dilakukan untuk memperkuat pelaksanaan penelitian ini. Hal ini bertujuan untuk mengkaji teori dasar yang sesuai dengan masalah yang diteliti. Kajian pustaka yang dipilih harus sesuai dengan masalah dan keterbaruan. Sehingga hasil dari penelitian ini akan relevan.

\subsection{Merumuskan Tujuan Penelitian}

Tujuan penelitian perlu disusun untuk mendeskripsikan sasaran dari penelitian ini. Dalam menyusun tujuan penelitian, diperlukan kalimat yang berupa pernyataan, dinyatakan dengan ringkas, jelas dan mengacu pada rumusan masalah.

\subsection{Merancang Penelitian}

Pada tahap ini, permasalahan yang muncul digali dengan melakukan observasi ke lapangan dan melalui wawancara dengan guru terkait penggunaan media pembelajaran. Observasi dilakukan kepada guru yang menggunakan media pembelajaran blog.

\subsection{Penentuan Objek Penelitian}

Pengambilan data guru yang aktif menggunakan blog sebagai media pembelajaran alternatif dan siswa maupun siswi yang mengakses blog dalam membantu proses belajar di sekolah maupun di luar sekolah. Data tersebut diperoleh dari guru dan siswa maupun siswi yang berasal dari beberapa sekolah SMK di wilayah kota Malang secara acak. Data ini diambil dengan membagikan kuesioner kepada guru dan siswa maupun siswi SMK.

\subsection{Pengumpulan Data}

Pada tahap ini akan dilakukan perencanaan terkait dengan langkah yang akan dilakukan peneliti sebelum menerapkan model UTAUT. Adapun langkah-langkah yang dilakukan pada tahap ini adalah:

(i) Membagikan kuesioner kepada guru SMK,

(ii) Mengambil sampel data guru yang menggunakan blog sebagai media pembelajaran,

(iii) Mengambil sampel data siswa maupun siswi yang mengakses blog sebagai media pembelajaran

(iv) Mempelajari model UTAUT,

(v) Menerapkan model UTAUT sebagai model penilaian penerimaan teknologi blog sebagai media pembelajaran.

\subsection{Analisis Hasil}

Analisis hasil dilakukan untuk mengetahui apakah model UTAUT yang diusulkan menghasilkan tingkat penerimaan teknologi blog sebagai media pembelajaran alternatif. Desain model UTAUT yang dibuat mengacu pada studi yang dilakukan oleh Venkatesh (Venkatesh, et al. 2003).

Tahapan selanjutnya setelah mendesain model UTAUT adalah menyusun kerangka kuesioner. Pembuatan kerangka kuesioner dibuat berdasarkan dari model UTAUT yang telah dibuat sebelumnya oleh Venkatesh.

Karena hasil dari angket dalam penelitian ini merupakan data kuantitatif, maka data tersebut akan dianalisis secara deskriptif persentase menggunakan rumus di bawah ini (Riduan, 2004).

$$
D P=\frac{n}{N} \times 100 \%
$$

DP merupakan deskriptif persentase, $n$ merupakan skor yang diperoleh dan $\mathrm{N}$ adalah skor ideal untuk setiap item pertanyaan. Nilai persentase yang diperoleh akan digunakan untuk mengetahui berapa persentase penggunaan blog pada penelitian ini yang lebih lengkapnya akan dibahas pada bab berikutnya.

\section{HASIL DAN PEMBAHASAN}

Untuk memperoleh hasil penelitian diperlukan sebuah instrumen penelitian. Dalam hal ini, kuesioner adalah instrumen yang tepat digunakan. Kuesioner yang digunakan telah dilakukan proses validasi dan reliabilitas terlebih dahulu.

Instrument penelitian yang telah disusun dan divalidasi, berikutnya akan diberikan kepada para guru SMK di Kota Malang. Jumlah guru yang dibagikan kuesioner ini sejumlah 61 guru SMK di Kota Malang.

Berdasarkan kuesioner yang dibagikan, maka data tersebut kemudian diolah dan dianalisis mengunakan rumus deskriptif persentase. Hasil persentase penggunaan blog ini dapat dilihat pada gambar di bawah ini.
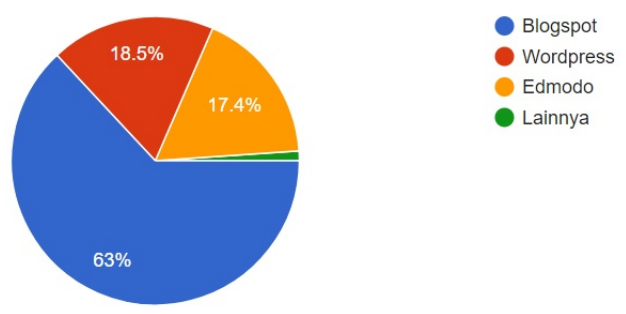

Gambar 3. Persentase Penggunaan Blog oleh Guru SMK

Berdasarkan gambar di atas, diperoleh bahwa guru yang menggunakan blogspot sebagai media pembelajaran adalah sebesar $63 \%$, wordpress sebesar $18.5 \%$, Edmodo sebesar $17.4 \%$ dan lainnya sebesar $1.1 \%$. Nilai presentase tersebut diperoleh dari banyaknya guru yang memilih media 
pembelajaran yang disebutkan dalam kuesioner dibagi.

Tabel 1. Rata-rata nilai variabel UTAUT

\begin{tabular}{lc}
\hline Variabel & Persentase (\%) \\
\hline Performance Expectancy & 81.80 \\
Effort Expectancy & 86.59 \\
Social Influence & 74.01 \\
Supporting Facilitating & 82.19 \\
Behavioral Intention & 82.86 \\
Use Behavior & 81.39 \\
\hline
\end{tabular}

Implementasi dari metode UTAUT ini diwujudkan dalam bentuk instrumen penelitian yang terdiri dari beberapa indikator/variabel. Dalam kuesioner yang digunakan terdapat 25 pernyataan dengan enam variabel yaitu performance expectancy, effort expectancy, social influence, supporting facilitating, behavioral intention dan use behavior.

Variabel performance expectancy memiliki definisi tentang persepsi individu terhadap sebuah sistem teknologi informasi pada kinerja pekerjaannya (Holden \& Karsh, 2010). Nilai ratarata yang diperoleh dari variabel tersebut adalah sebesar 81.80 yang memiliki nilai sangat tinggi jika dibandingkan dengan tabel normal. Hal ini memiliki makna bahwa blog sebagai alternatif media pembelajaran c, yaitu blog. Karena performance expectancy memiliki dampak secara langsung terhadap penggunaan teknologi tersebut (Carlsson 2006).

Variabel effort expectancy memiliki definisi tentang kemudahan penggunaan yang ada dalam sistem (Venkatesh, et al. 2003). Berdasarkan penelitian yang telah dilakukan, diperoleh hasil ratarata dari variabel effort expectancy sebesar 86.59. Nilai tersebut bermakna bahwa blog gratis memiliki kemudahan dalam penggunaannya sebagai media pembelajaran bagi user, dalam hal ini adalah guru. Effort expectancy menjadi faktor penting dalam menggunakan teknologi melalui smartphone (C. Carlsson, 2006).

Variabel social influence memiliki definisi derajat sejauh mana seorang individu merasakan pentingnya bahwa orang lain percaya ia harus menggunakan sistem baru (Venkatesh, et al. 2003). Berdasarkan penelitian yang telah dilakukan, diperoleh hasil rata-rata dari variabel social influence sebesar 74.01. Nilai tersebut bermakna bahwa pengaruh lingkungan sosial juga dapat menjadi pendorong seorang guru untuk menggunakan blog gratis sebagai media pembelajaran bagi user, dalam hal ini adalah lingkungan kerja guru yang secara dominan di sekolah. Social influence menjadi faktor pendukung terbesar dalam penggunaan sistem baru oleh seseorang karena dipengaruhi oleh dorongan oleh orang-orang di sekitarnya (Bozan, Parker and Davey 2016).

Variabel supporting facilitating didefinisikan sebagai sejauh mana seorang individu percaya bahwa infrastruktur organisasi dan teknis ada untuk mendukung penggunaan sistem (Venkatesh, et al. 2003). Nilai rata-rata yang diperoleh dari variabel tersebut adalah sebesar 82.19. Hal ini memiliki makna bahwa kondisi fasilitas sekolah yang menunjang pembelajaran sudah sangat mampu untuk dapat digunakan mengakses blog sebagai penunjang dalam kegiatan belajar mengajar. Variabel supporting facilitating menunjukkan bahwa dukungan fasilitas yang baik dalam sebuah aktivitas sangat penting sehingga tujuan dari sebuah aktivitas tersebut dapat tercapai seperti yang dinginkan (Ghalandari, 2012).

Variabel behavioral intention mewakili tentang cara seseorang pengguna dalam menggunakan sistem (Venkatesh, et al. 2003). Nilai rata-rata yang diperoleh dari variabel tersebut adalah sebesar 82.86. Hal ini memiliki makna bahwa penggunaan blog sebagai alternatif media pembelajaran dapat diterima dengan sangat baik oleh para guru dan mereka tertarik untuk menggunakannya dalam kegiatan belajar mengajar. Penggunaan teknologi digital, seperti blog dalam kegiatan belajar mengajar dapat menjadikan pembelajaran berjalan lebih baik, efektif dan efisien sehingga tujuan pembelajaran dapat tercapai lebih baik lagi daripada sebelumnya (Higgins, Xiao and Katsipataki, 2012).

Variabel use behaviour mewakili perilaku seseorang saat dia menggunakan sistem. Use behavior adalah bukti akhir dari penerimaan seseorang terhadap sebuah teknologi yang ditunjukkan pada bagaimana perilaku yang dia lakukan saat menggunakan sistem (Venkatesh, et al. 2003). Nilai rata-rata yang diperoleh dari variabel tersebut adalah sebesar 81.39. Hal ini memiliki makna bahwa blog sebagai alternatif media pembelajaran sangat diterima oleh guru-guru SMK di lingkungan kota Malang karena membantu meningkatkan kinerja mereka dalam kegiatan belajar mengajar. Variabel use behavior menjadi bukti bahwa sebuah teknologi diterima oleh penggunanya dan mereka percaya bahwa teknologi tersebut dapat membantu aktivitas mereka secara lebih baik (Bozan, Parker and Davey, 2016, Higgins, Xiao and Katsipataki, 2012).

\section{KESIMPULAN}

Berdasarkan hasil survey dan observasi yang dilakukan didapatkan hasil bahwa sebanyak 63\% guru SMK di wilayah kota Malang atau setara dengan 58 orang menggunakan blogspot sebagai penyedia layanan blog gratis, $18.5 \%$ guru SMK di wilayah kota Malang atau setara dengan 17 orang menggunakan wordpress sebagai penyedia layanan blog gratis, $17.4 \%$ guru SMK di wilayah kota Malang atau setara dengan 16 orang menggunakan 
edmodo sebagai penyedia layanan weblog gratis dan $1.1 \%$ guru SMK di wilayah kota Malang atau setara dengan 1 orang menggunakan facebook sebagai penyedia layanan weblog gratis.

Implementasi model UTAUT sebagai model dasar dalam penilaian penerimaan teknologi blog sebagai media pembelajaran alternatif pada SMK dapat dilakukan dengan membuat kuesioner sesuai dengan variabel dan instrumen penelitian penerimaan sistem, kemudian membagikannya pada 61 guru SMK di kota Malang dengan teknik random sampling dan kemudian dilakukan analisis terhadap hasil tersebut. Sesuai dengan hasil analisis pengujian yang dilakukan didapatkan hasil bahwa variabel performance expectancy memiliki nilai rata-rata sebesar 81.80, variabel effort expectancy memiliki nilai rata-rata 86.59 , variabel social influence memiliki nilai rata-rata 74.01 , variabel supporting facilitating memiliki nilai rata-rata sebesar 82.19, variabel behavioral intention memiliki nilai rata-rata sebesar 82.86, dan variabel use behavior memiliki nilai rata-rata sebesar 81.39. Berdasarkan nilai-nilai tersebut yang berada pada range nilai diatas 75 , hal ini dapat disimpulkan bahwa penggunaan blog memang membantu guru dalam melaksanakan pekerjaannya. Sedangkan kebanyakan guru mengetahui informasi tentang blog bukan dari orang-orang di sekitarnya. Namun karena keingintahuannya dalam mencari teknologi yang dapat digunakan dalam pekerjaannya. Hal ini terlihat dengan nilai social influence yang dihasilkan.

\section{DAFTAR PUSTAKA}

BOZAN, K., PARKER, K. \& DAVEY, B., 2016. A Closer Look at the Social Influence Construct in the UTAUT Model: An Institutional Theory Based Approach to Investigate Health IT Adoption Patterns of the Elderly. Hawaii, IEEE Computer Society.

C. CARLSSON, J. C. K. H. J. P. P. W., 2006. Adoption of mobile devices/services Searching for answers with the UTAUT. 6(132a-132a).

CARLSSON, B., 2006. Internationalization of innovation systems: a survey of the literature. 35(56-67).

CHANDRAWATI, S. R., 2010. Pemanfaatan Elearning dalam Pembelajaran. 8(2).

DAMARJATI, T., 2016. Uji Kompetensi Keahlian Final.

[Online]

Available at: https://psmk.kemdikbud.go.id/konten/2143/uj i-kompetensi-keahlian

[Accessed 14 March 2017]

GHALANDARI, K., 2012. The Effect of Performance Expectancy, Effort Expectancy,. 12(6).

HERUTOMO, A., 2010. Conquering Web 2.0. Jakarta: PT Elex Media Komputindo.
HIGGINS, S., XIAO, Z. \& KATSIPATAKI, M., 2012. The Impact of Digital Technology on Learning:, Durham: Durham University.

KURNIABUDI, SETIAWAN ASSEGAFF. 2016. Analisis Perilaku Penerimaan EDMODO pada Perkuliahan Dengan Model UTAUT. Jurnal Teknologi dan Sistem Informasi. 2(3).

LIU, M.-H., 2016. Blending a class video blog to optimize student learning outcomes in higher education. Internet and Higher Education, pp. 44-53.

PRADANA, FAJAR, RACHMADI, ADITYA, BACHTIAR, A. FITRAH. 2015. Penilaian Faktor Penerimaan Teknologi Blended Learning di PTIIK Universitas Brawijaya dengan Metode UTAUT. Jurnal JTIIK. 2(1).

PUJIANI, I., 2014. Persiapan Indonesia dalam MEA (Masyarakat Ekonomi ASEAN). [Online] Available at: http://id.stiestmy.ac.id/halkomentar-165-persiapanindonesia-dalam-menghadapi-meamasyarakat-ekonomi-22515.html [Accessed 8 April 2017].

SEAMOLEC. 2016. Pembuatan Blog Sebagai Media Pembelajaran. [Online]. Tersedia di $<$ https://drive.google.com/file/d/0Bw121JMb dp1ET3E5eUJjZkd1Zk0/view> [Diakses pada tanggal 25 April 2017]

SEAMOLEC. 2016. Pengenalan Media Pembelajaran. [Online] $<$ https://youtu.be/PJ0L_U5WPrY $>$ [Diakses pada tanggal 25 April 2017]

$\begin{gathered}\text { SEAMOLEC, } \\ \text { Available }\end{gathered} 2017 . \quad$ [Online] https://drive.google.com/file/d/0Bw121JMbdp 1ET3E5eUJjZkd1Zk0/view

[Accessed 25 April 2017].

SUJATA S. KATHPALIA, E. K. S., 2016. Improving argumentation through student blogs. System, pp. 25-36.

SUSANTO, H., 2011. [Online] Available at: http://www.kompasiana.com/harisusanto/pen gertian-dan-sejarahblog_55006e3ba33311fb6f510fd6 [Accessed 10 March 2017].

VENKATESH, V., MORRIS, M., DAVIS, G. \& DAVIS, F., 2003. User acceptance of information technology: toward a unified view. Issue 425-478. 